Article

\title{
High Specificity of BCL11B and GLG1 for EWSR1-FLI1 and EWSR1-ERG Positive Ewing Sarcoma
}

\author{
Martin F. Orth ${ }^{1}\left(\mathbb{D}\right.$, Tilman L. B. Hölting ${ }^{1, \dagger}{ }^{\text {, Marlene Dallmayer }}{ }^{1,2,+}{ }^{\text {, Fabienne S. Wehweck }}{ }^{1,3}$, \\ Tanja Paul ${ }^{1,3}$, Julian Musa ${ }^{1,4} \mathbb{D}^{D}$, Michaela C. Baldauf ${ }^{1}$, Didier Surdez ${ }^{5}$, Olivier Delattre ${ }^{5}$, \\ Maximilian M. L. Knott ${ }^{1,3}{ }^{(D)}$, Laura Romero-Pérez ${ }^{1}$ (D), Merve Kasan ${ }^{1}$ (D), \\ Florencia Cidre-Aranaz ${ }^{1} \mathbb{D}$, Julia S. Gerke ${ }^{1}$, Shunya Ohmura ${ }^{1} \mathbb{D}$, Jing Li ${ }^{1}$, Aruna Marchetto ${ }^{1}$, \\ Anton G. Henssen ${ }^{6,7}$, Özlem Özen ${ }^{8}$, Shintaro Sugita ${ }^{9}$, Tadashi Hasegawa ${ }^{9}$, \\ Takayuki Kanaseki ${ }^{10}$, Stefanie Bertram ${ }^{11}$, Uta Dirksen 12,13 (D), Wolfgang Hartmann ${ }^{14}$, \\ Thomas Kirchner ${ }^{3,15,16}$ and Thomas G. P. Grünewald 1,3,15,16,*(D)
}

1 Max-Eder Research Group for Pediatric Sarcoma Biology, Institute of Pathology, Faculty of Medicine, LMU Munich, 80337 Munich, Germany; Martin.Orth@med.uni-muenchen.de (M.F.O.); Tilman.Hoelting@med.uni-muenchen.de (T.L.B.H.); Marlene.Dallmayer@ukmuenster.de (M.D.); Fabienne.Wehweck@med.uni-muenchen.de (F.S.W.); Tanja.Paul@med.uni-muenchen.de (T.P.); Julian.Musa@med.uni-muenchen.de (J.M.); Michaela.Baldauf@med.uni-muenchen.de (M.C.B.); Maximilian.Knott@med.uni-muenchen.de (M.M.L.K.); Laura.Romeroperez@med.uni-muenchen.de (L.R.-P.); Merve.Kasan@med.uni-muenchen.de (M.K.); Florencia.Cidre_Aranaz@med.uni-muenchen.de (F.C.-A.); Julia.Gerke@med.uni-muenchen.de (J.S.G.); Shunya.Ohmura@med.uni-muenchen.de (S.O.); Jing.Li@med.uni-muenchen.de (J.L.); Aruna.Marchetto@med.uni-muenchen.de (A.M.)

2 Department of Pediatrics, University Hospital Münster, 48149 Münster, Germany

3 Institute of Pathology, Faculty of Medicine, LMU Munich, 80337 Munich, Germany; Thomas.Kirchner@med.uni-muenchen.de

4 Department of General, Visceral and Transplantation Surgery, University of Heidelberg, 69120 Heidelberg, Germany

5 INSERM Unit 830 'Genetics and Biology of Cancers', Institut Curie Research Center, 75248 Paris, France; Didier.Surdez@curie.fr (D.S.); Olivier.Delattre@curie.fr (O.D.)

6 Department of Pediatric Hematology/Oncology/BMT, Charité-University Medicine Berlin, 13353 Berlin, Germany; anton.henssen@charite.de

7 Experimental and Clinical Research Center (ECRC) of the MDC and Charité Berlin, 13125 Berlin, Germany

8 Department of Pathology, Başkent University Hospital, Ankara 06490, Turkey; ozlemis@yahoo.com

9 Department of Surgical Pathology, Sapporo Medical University, Sapporo 060-8556, Japan; ssugita@sapmed.ac.jp (S.S.); hasegawa@sapmed.ac.jp (T.H.)

10 Department of Pathology, Sapporo Medical University, Sapporo 060-8556, Japan; kanaseki@sapmed.ac.jp

11 Institute of Pathology, University Hospital Essen, 45147 Essen, Germany; Stefanie.Bertram@uk-essen.de

12 Pediatrics III, AYA Unit, West German Cancer Centre, University Hospital Essen, 45147 Essen, Germany; Uta.Dirksen@uk-essen.de

13 German Cancer Consortium (DKTK), Partner Site Essen, 45147 Essen, Germany

14 Division of Translational Oncology, Gerhard-Domagk-Institute for Pathology, University Hospital Münster, 48149 Münster, Germany; Wolfgang.Hartmann@ukmuenster.de

15 German Cancer Consortium (DKTK), Partner Site Munich, 80336 Munich, Germany

16 German Cancer Research Center (DKFZ), 69120 Heidelberg, Germany

* Correspondence: thomas.gruenewald@med.uni-muenchen.de; Tel.: +49-89-2180-73716

+ Equal contribution.

Received: 26 February 2020; Accepted: 8 March 2020; Published: 10 March 2020

Abstract: Ewing sarcoma (EwS) is an aggressive cancer displaying an undifferentiated small-round-cell histomorphology that can be easily confused with a broad spectrum of differential diagnoses. Using comparative transcriptomics and immunohistochemistry (IHC), we previously identified BCL11B and 
GLG1 as potential specific auxiliary IHC markers for EWSR1-FLI1-positive EwS. Herein, we aimed at validating the specificity of both markers in a far larger and independent cohort of EwS (including EWSR1-ERG-positive cases) and differential diagnoses. Furthermore, we evaluated their intra-tumoral expression heterogeneity. Thus, we stained tissue microarrays from 133 molecularly confirmed EwS cases and 320 samples from morphological mimics, as well as a series of patient-derived xenograft (PDX) models for BCL11B, GLG1, and CD99, and systematically assessed the immunoreactivity and optimal cut-offs for each marker. These analyses demonstrated that high BCL11B and/or GLG1 immunoreactivity in CD99-positive cases had a specificity of $97.5 \%$ and an accuracy of $87.4 \%$ for diagnosing EwS solely by IHC, and that the markers were expressed by EWSR1-ERG-positive EwS. Only little intra-tumoral heterogeneity in immunoreactivity was observed for differential diagnoses. These results indicate that BCL11B and GLG1 may help as specific auxiliary IHC markers in diagnosing EwS in conjunction with CD99, especially if confirmatory molecular diagnostics are not available.

Keywords: Ewing sarcoma; biomarkers; immunohistochemistry; diagnostics; BCL11B; GLG1

\section{Introduction}

Ewing sarcoma (EwS) is an undifferentiated small-round-cell sarcoma driven by FET-ETS fusion oncoproteins [1]. EwS constitutes the second most common bone-associated sarcoma in children, adolescents, and young adults after osteosarcoma [1-3]. However, EwS also occurs in soft tissue, although less frequently and predominantly in older patients $[4,5]$.

In more than $30 \%$ of cases, micrometastases are present at time of diagnosis [6]. For these patients, outcome is rather poor with a long-term survival rate of around $25 \%$ [6-8], with a slightly better survival rate for patients exhibiting exclusively lung metastases $[9,10]$. Nevertheless, patients with localized (i.e., non-metastatic) disease can be effectively treated with combined chemotherapy and surgery [11-13], resulting in a long-term survival rate of more than 70\% [14-16]. Besides metastasis, larger tumor size also correlates negatively with patients' overall survival [8]. Although there is an ongoing debate whether time to diagnosis is associated with metastasis and survival of individuals affected by EwS $[17,18]$, early and robust diagnosis of EwS is important to assign patients quickly to the appropriate therapy and to avoid unnecessary delay in treatment.

From a morphological point of view, histopathological diagnosis of EwS has been notoriously difficult due to its highly undifferentiated small-round-cell phenotype being shared with a variety of differential diagnoses [19], such as neuroblastoma, rhabdomyosarcoma, lymphoblastic lymphoma, desmoplastic small round cell tumor (DSRCT), and round-cell liposarcoma [20-25].

For almost three decades, the standard immunohistochemical marker for EwS has been the membranous glycoprotein CD99 [1,26], which shows a striking sensitivity but low specificity for EwS [27-31]. Since fusions of the FET family of genes comprising FUS, EWSR1, and potentially TAF15, with members of the ETS family of transcription factors (including FLI1, ERG, ETV1/4/6 and FEV) are largely pathognomonic for EwS [32-34], molecular identification of such fusions is the most reliable diagnostic test for EwS to date [24]. The most common fusion genes are EWSR1-FLI1 and EWSR1-ERG, occurring in around $85 \%$ and $10 \%$ of cases, respectively.

However, many current standard methods used for molecular diagnosis in pathology are not infallible. For instance, PCR analyses may fail to detect all FET-ETS variants unless multiplexed PCRs covering all known variants are employed $[35,36]$. In addition, fluorescence in situ hybridization (FISH) approaches, commonly used to detect EWSR1 break-apart, can miss EwS cases with FUS-ETS fusions [37], are often challenging in EWSR1-ERG-positive EwS [38], or can be misleading in morphological mimics, such as DSRCT harboring pathognomonic EWSR1-WT1 fusions $[24,39,40]$ or EWSR1-NFATc2 fusion positive small-round-cell sarcomas [40-42]. 
Therefore, a progressively increasing number of institutes nowadays employ more advanced approaches as auxiliary methods to confirm or rule out the diagnosis of EwS, such as next-generation sequencing (NGS) to directly sequence the fusion transcripts [43] and/or microarray-based methylation-profiling [41,44].

However, these sophisticated molecular diagnostic tools are not available at every institution worldwide and, in some cases, not feasible due to the quantity and/or quality of the available tumor specimen. Therefore, we strived to identify highly specific auxiliary diagnostic markers that can be detected by widely available and inexpensive immunohistochemistry (IHC) [27]. Using comparative transcriptomics in EwS and 20 morphological mimics, we previously identified the proteins BCL11B (B-cell lymphoma/leukemia 11B) and GLG1 (Golgi apparatus protein 1) as potential auxiliary markers that can support the diagnosis of EwS [27]. Besides BCL11B and GLG1, out of all 19,702 genes represented on the employed microarray platform, only ATP1A1 showed significant overexpression (log2 expression difference $>2$ ) in EwS compared to samples of the 20 morphological mimics tested [27]. Hence, BCL11B, GLG1, and ATP1A1 appeared as most promising auxiliary markers for diagnosing EwS by immunohistochemistry.

BCL11B is a transcription factor mainly involved in T cell development, which was previously identified as a direct EWSR1-FLI1 target gene contributing to the malignant phenotype of EwS [45]. GLG1 encodes a glycoprotein of still unknown function, even though it was first described in humans in 1990 [46]. In our discovery study (Baldauf et al. 2018) comprising $47 \mathrm{EwS}$ cases and 127 samples of morphological mimics on tissue microarrays (TMAs) [27], we found that both proteins are highly overexpressed in the majority of EwS primary tumors, which is likely due to binding of EWSR1-FLI1 to super-enhancer regions spanning their encoding genes [27]. Although analyses for ATP1A1 showed the same results, ATP1A1 did neither improve sensitivity nor specificity of the marker combination, and was not further investigated [27].

In the current study, we aimed at (I) validating the high specificity of BCL11B and GLG1 overexpression for EwS in a new, much larger, and independent cohort, (II) testing the applicability of these markers also for EWSR1-ERG-positive EwS, and (III) determining the degree of intra-tumoral marker heterogeneity. To this end, TMAs of 453 cases including 133 EwS cases and 320 cases from 11 differential diagnoses were constructed and stained for BCL11B, GLG1, and CD99. Immunoreactivity was assessed independently by three researchers based on a modified Remmele and Stegner scoring system [47].

Our results confirm the high specificity of BCL11B and GLG1 for EwS regardless of the underlying fusion type, enabled the refinement of cut-off values for classifying cases as 'positive' or 'negative' for the given marker, and revealed intra-tumoral heterogeneity of the proposed auxiliary markers to be negligible in differential diagnoses for EwS. These findings lead us to propose a work-flow for diagnosing EwS on the basis of IHC detection of CD99, BCL11B, and GLG1, which could be widely applied independent of the availability of molecular pathology diagnostics.

\section{Results}

\subsection{IHC for CD99 and FISH for EWSR1 Break-Apart Are Not Fully Sufficient to Diagnose EwS}

The histological small-round-cell phenotype is shared by several cancer entities including EwS. Therefore, if such histology is present and EwS is suspected, fluorescence in situ hybridization (FISH) for detection of EWSR1 break-apart and immunohistochemical CD99 stains are commonly performed in pathological routine diagnostics for exclusion or diagnosis of EwS [1]. Yet, EWSR1 break-apart occurs in several morphological mimics of EwS such as DSRCT harboring a pathognomonic EWSR1-WT1 fusion, and angiomatoid fibrous histiocytoma (AFH) commonly positive for EWSR1-ATF1 fusions (Figure 1). 


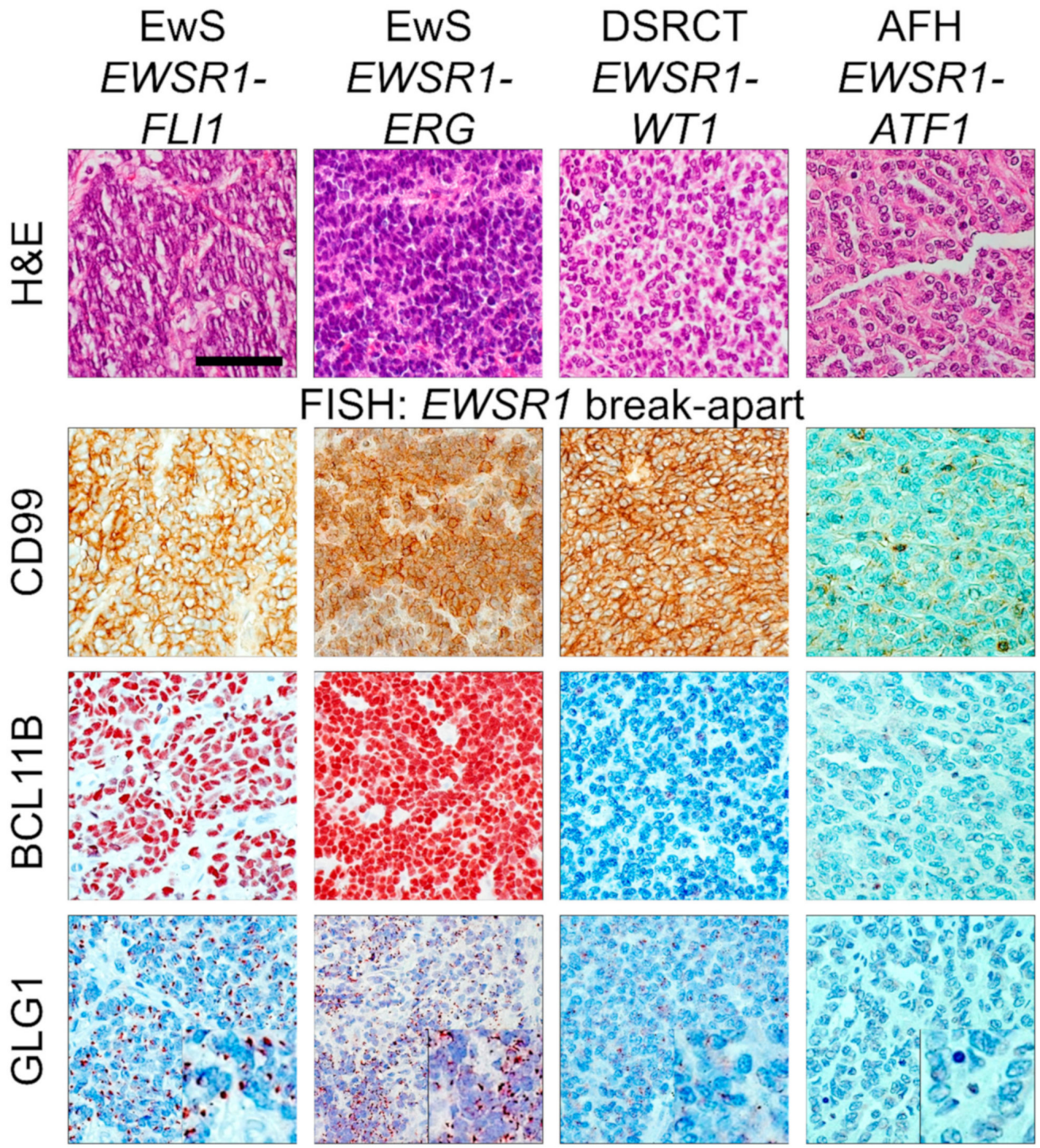

Figure 1. Immunohistochemistry (IHC) for CD99 and fluorescence in situ hybridization (FISH) for EWSR1 break-apart are not sufficient to constitute the diagnosis EwS. From left to right: representative micrographs of Ewing sarcoma (EwS) positive for EWSR1-FLI1 or EWSR1-ERG, desmoplastic small round cell tumor (DSRCT) positive for EWSR1-WT1, and an angiomatoid fibrous histiocytoma (AFH) positive for EWSR1-ATF1, stained with H\&E, or for CD99, BCL11B, and GLG1. The scale bar applies to all micrographs and indicates $40 \mu \mathrm{m}$, insets for GLG1 are enlarged by factor two. In all cases, an EWSR1 break-apart was detected by FISH.

CD99 is the standard IHC marker in pathological workup of potential EwS samples [26]. However, to the best of our knowledge, no international guidelines were established on how to standardize the scoring and interpretation of CD99 immunoreactivity in EwS. In addition, CD99 is highly expressed in several other cancer types [48-50], and its specificity for EwS among differential diagnoses was found to be remarkably low in our previous study (17\% at a cut-off of 2 [27]).

To further assess the sensitivity and specificity of CD99 immunoreactivity for EwS, we systematically scored CD99 immunoreactivity using our modified Remmele and Stegner scoring system in a series of $n=133$ molecularly confirmed EwS tumors and $n=320$ morphological mimics from 11 differential diagnoses (Table 1). 
Table 1. Composition of the tissue microarrays (TMAs). EwS, Ewing sarcoma; DSRCT, desmoplastic small round cell tumor; GIST, gastrointestinal stromal tumor; dediff, dedifferentiated.

\begin{tabular}{cc}
\hline Tumor Entity & $n$ \\
\hline EwS & 133 \\
Chondrosarcoma & 23 \\
DSRCT & 7 \\
GIST & 13 \\
Hepatoblastoma & 23 \\
Leiomyosarcoma & 45 \\
Liposarcoma (dediff./myxoid) & $26(17 / 9)$ \\
Nephroblastoma & 33 \\
Neuroblastoma & 92 \\
Osteosarcoma & 29 \\
Rhabdomyosarcoma & 19 \\
Synovial sarcoma & 10 \\
\hline total & 453 \\
\hline
\end{tabular}

In this cohort, CD99 showed high sensitivity for EwS ranging from $100 \%$ at an immunoreactive score (IRS) cut-off of $>0$ to $88 \%$ for an IRS cut-off of $>9$ (Table 2). However, the specificity of CD99 immunoreactivity proved to be rather low ranging from $2.5 \%$ to $67.5 \%$ depending on the chosen cut-off (Table 2). Even the highest CD99 IRS score of 12 was observed in some instances of morphological mimics of EwS, such as DSRCT (Figure 1). Accordingly, the high sensitivity of CD99 for EwS even at high IRS cut-offs may indicate that only strongly CD99 positive samples should be considered as potential EwS, and that samples only faintly stained for CD99 should be rather regarded as "negative".

Table 2. Sensitivity and specificity of CD99 immunoreactivity in EwS. IRS, immunoreactive score.

\begin{tabular}{ccc}
\hline $\begin{array}{c}\text { Cut-Off } \\
\text { (CD99 IRS > Indicated Value) }\end{array}$ & Sensitivity (\%) & Specificity (\%) \\
\hline 0 & 100.0 & 2.5 \\
1 & 100.0 & 6.6 \\
2 & 100.0 & 10.0 \\
3 & 99.2 & 18.1 \\
4 & 98.5 & 26.9 \\
6 & 95.5 & 43.8 \\
8 & 91.0 & 60.0 \\
9 & 88.0 & 67.5 \\
\hline
\end{tabular}

Collectively, the representative cases shown in Figure 1 and our systematic scoring of CD99 demonstrate that the detection of an EWSR1 break-apart in FISH in conjunction with immunoreactivity for CD99 are not fully sufficient to robustly diagnose EwS, suggesting that more sophisticated molecular pathology techniques, such as qRT-PCR, RNA-sequencing [51,52] or comparative methylation profiling [41,44], should be employed. Alternatively, highly specific auxiliary immunohistochemical markers could be used in conjunction with CD99 to compensate for its lack of specificity. In our prior discovery study, we proposed, based on comparative transcriptomics and preliminary immunohistochemical validation, BCL11B and GLG1 as potentially useful auxiliary markers for immunohistochemical diagnosis of EwS [27]. Indeed, the high and distinct nuclear (BCL11B) or perinuclear (GLG1) expression of both markers was very helpful to establish the diagnosis of EwS in the two representative EwS cases shown in Figure 1, which were molecularly verified by next-generation sequencing (NGS; Archer FusionPlex Sarcoma panel). 


\subsection{High Immunoreactivity for BCL11B and/or GLG1 Is Specific for EwS}

To assess the diagnostic value of the proposed auxiliary markers BCL11B and GLG1, all 453 cases of our new cohort (Table 1), were semi-quantitatively scored for their immunoreactivity using a modified Remmele and Stegner [47] scoring system (see Methods).

We observed that BCL11B and GLG1 were highly expressed in EwS. In fact, $75.9 \%$ of EwS cases (101/133) were highly reactive for at least one marker, co-expression of both was detected in $32.3 \%$ of EwS cases (43/133) (Figure 2a,b); $48.9 \%$ of cases (65/133) exhibited high immunoreactivity for BCL11B and $59.4 \%$ (79/133) for GLG1. High immunoreactivity was set as $60 \%$ of EwS cells per sample stained with at least intermediate intensity (IRS $\geq 6$ ).

a

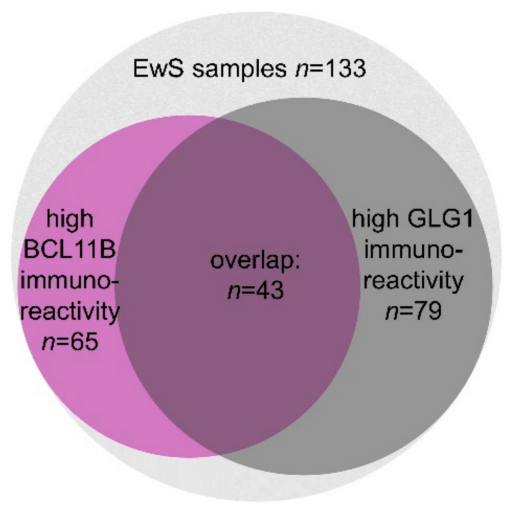

b

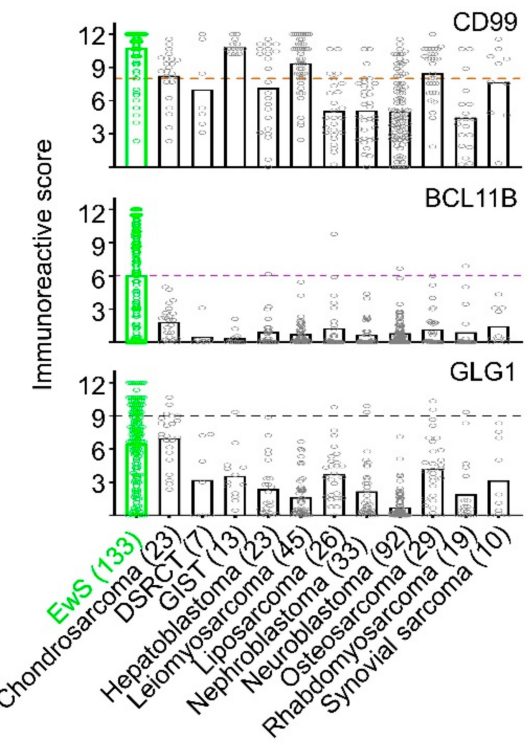

Figure 2. High immunoreactivity for BCL11B and GLG1 is diagnostic for EwS in CD99 positive samples. (a) Venn diagram representing all EwS samples in the TMA cohort of this study, the BCL11B and GLG1 high-expressing samples (at least 60\% tumor cells stained, at least intermediate intensity) and their overlap. (b) Dot-plots indicating IRS values for CD99, BCL11B, and GLG1 in EwS and 11 differential diagnoses. The number of samples per entity is given in brackets. Bars indicate mean IRS; dashed lines indicate optimal cut-offs.

As CD99 proved to be highly sensitive for EwS in our cohort, we considered only those samples as potential EwS with a CD99 IRS of at least 2 (100\% sensitivity for EwS; Figure $2 b)$. To define the diagnostically most informative combination of BCL11B and GLG1 immunoreactivity for EwS (only one marker positive/ at least one positive/ both positive; each marker with all different mathematically possible IRS cut-offs), we performed automated sensitivity and specificity calculations. To this end, we focused on combinations with the highest specificity for EwS, because lack of specificity is a major issue of routinely applied diagnostic tools in EwS.

After filtering out all marker combinations with a specificity for EwS $<95 \%$, we selected the marker combination with the highest sensitivity. Through this process, we noted the positivity of at least one marker with IRS cut-offs $>6$ and $>9$ for BCL11B and GLG1, respectively, to be highly specific (95.6\%) but moderately sensitive (64.7\%) for EwS (Figure 2b). Interestingly, CD99 with an IRS cut-off $>2$ did not raise the specificity of this marker combination. Only at an IRS cut-off $>8$ for CD99, the specificity for immunohistochemical diagnosis of EwS could be slightly increased to $97.5 \%$, while the sensitivity slightly dropped to $63.2 \%$.

To test, whether this marker specificity is not limited to the most common fusion type in EwS (EWSR1-FLI1), open slides of six molecularly confirmed EWSR1-ERG-positive EwS cases were stained for BCL11B and GLG1. Strikingly, BCL11B exhibited in all cases the highest possible IRS of 12 (for example see Figure 1), while the IRS for GLG1 ranged from 0-8. 
We previously showed that BCL11B and GLG1 mRNA expression is upregulated by EWSR1-FLI1 in EwS cell lines harboring this specific fusion type [27]. To test whether the marker transcripts can be upregulated also by EWSR1-ERG, we assessed their expression by qRT-PCR in three EWSR1-ERG-positive EwS cell lines with/without RNA interference-mediated EWSR1-ERG silencing. As shown in Supplementary Figure S1a, knockdown of EWSR1-ERG was accompanied by downregulation of BCL11B and GLG1 expression in all three cell lines tested, suggesting that these markers are also upregulated by EWSR1-ERG in EwS harboring this fusion (around 10\% of cases). In conjunction with the scoring results of the six molecularly confirmed EWSR1-ERG-positive EwS cases, these experimental results further suggest that high expression of both marker proteins in primary EwS is not restricted to EWSR1-FLI1-positive tumors.

Since patient-derived xenografts (PDX) are increasingly used as preclinical models to study EwS biology [48], we tested the expression pattern of BCL11B and GLG1 in PDX from EwS and non-EwS patients (18 PDX models originating from 15 EwS patients; 52 PDX models originating from 49 non-EwS patients). As expected, expression of both markers was higher for PDX from EwS patients as compared to the non-EwS PDX (Supplementary Figure S1b). Interestingly, the tested series of PDX models included five samples from so-called 'Ewing-like' sarcomas (3 CIC-DUX4-positive sarcomas and 2 BCOR-rearranged sarcomas), which did not exhibit any BCL11B and GLG1 immunoreactivity. These findings in PDX models further support the high specificity of BCL11B and GLG1 for EwS.

\subsection{BCL11B and GLG1 Exhibit Low Intra-Tumoral Heterogeneity in Differential Diagnoses for EwS}

Tumor material is often limited in pathological workup (e.g., in needle/punch biopsies). In the context of histological tumor evaluation, limited material can lead to substantial confusion in case of high intra-tumoral heterogeneity of morphology and diagnostic marker expression. Therefore, the heterogeneity of scoring for CD99, BCL11B, and GLG1 in different cores per sample, originating from different regions of a given tumor block, was assessed. For non-EwS, 248 samples with three cores per marker were available in our TMA-cohort. Samples were classified as high or low for the different markers applying the thresholds defined above (Figure $2 b$ ).

For CD99, 81\% of non-EwS tumor samples were classified consistently across all three cores per sample, for BCL11B 97.6\%, and for GLG1 and 94.8\% (Figure 3), indicating only little intra-tumoral heterogeneity in EwS differential diagnoses. When combining the three markers, in 95.2\% of all non-EwS samples all three cores were classified consistently as EwS or non-EwS. Hence, even when only little material of non-EwS cases is available, misclassification as EwS because of marker heterogeneity is highly unlikely, and the specificity of the markers is not affected. The observed intra-tumoral heterogeneity in differential diagnosis for EwS can therefore be regarded as rather negligible.

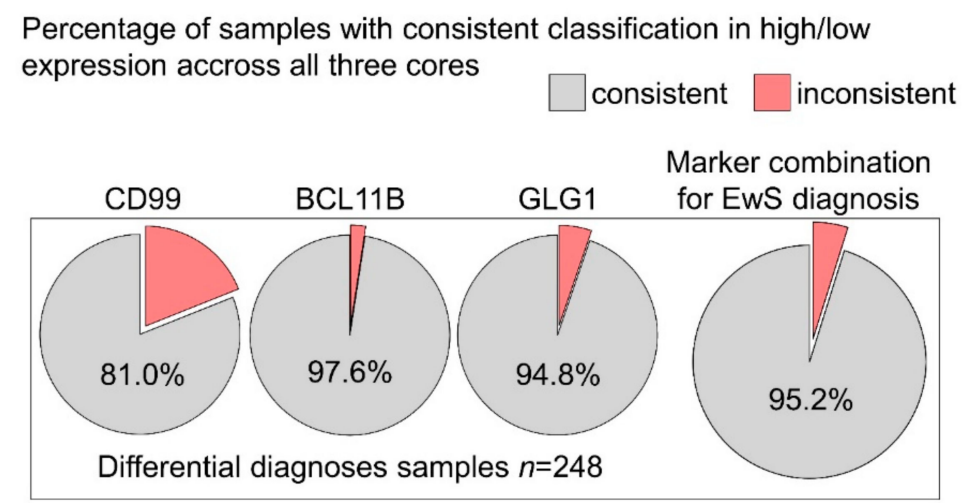

Figure 3. BCL11B and GLG1 show low intra-tumoral expression heterogeneity in differential diagnosis for EwS. Pie charts indicating non-EwS samples with three cores evaluated in each staining $(n=248)$ that were classified as high- or low-expressing the respective marker consistently (grey) or inconsistently (light red) across all three cores. 
In our TMA-cohort, most EwS samples were represented by two cores. For $n=96$ EwS cases two cores were present in each staining. In these $96 \mathrm{EwS}$ cases, we found consistent classification as marker-positive or -negative in 81.1\%-87.4\% (Supplementary Figure S2).

In sum, these results suggest that the combination of CD99 as a screening marker and the highly specific auxiliary markers BCL11B and GLG1 may be applicable even in cases where only scarce material is available.

\subsection{Proposed Work-Flow for Immunohistochemical Assessment of EwS}

Given the above-mentioned results and in support of the findings of Baldauf et al. 2018 [27], we propose the following work-flow for immunohistochemical assessment of EwS: First, CD99 staining should be performed. If the IRS is equal or lower than 8 , the suspected diagnosis should be reconsidered. In cases with a CD99 IRS greater than 8 (meaning strong membranous staining intensity in at least $60 \%$ of tumor cells), the diagnosis of EwS should be either confirmed by molecular pathology approaches that can reliably detect FET-ETS fusions such as qRT-PCR or RNA-seq, or by immunohistochemical staining for the auxiliary markers BCL11B and GLG1.

The diagnosis of EwS can be confidently established in case of high BCL11B immunoreactivity (IRS >6; i.e., moderate nuclear staining intensity in at least $80 \%$ of tumor cells, or strong nuclear staining intensity in at least $60 \%$ of tumor cells) and/or high GLG1 immunoreactivity (IRS >9; i.e., strong perinuclear staining in at least $80 \%$ of tumor cells). If both markers show immunoreactivity scores below the respective cut-off, the diagnosis of EwS should be molecularly confirmed (Figure 4a). Applying this algorithm to our cohort of 133 EwS cases and 320 cases from differential diagnoses yields a positive predictive value of $91.3 \%$ and a negative predictive value of $86.4 \%$ (Figure $4 \mathrm{~b}$ )

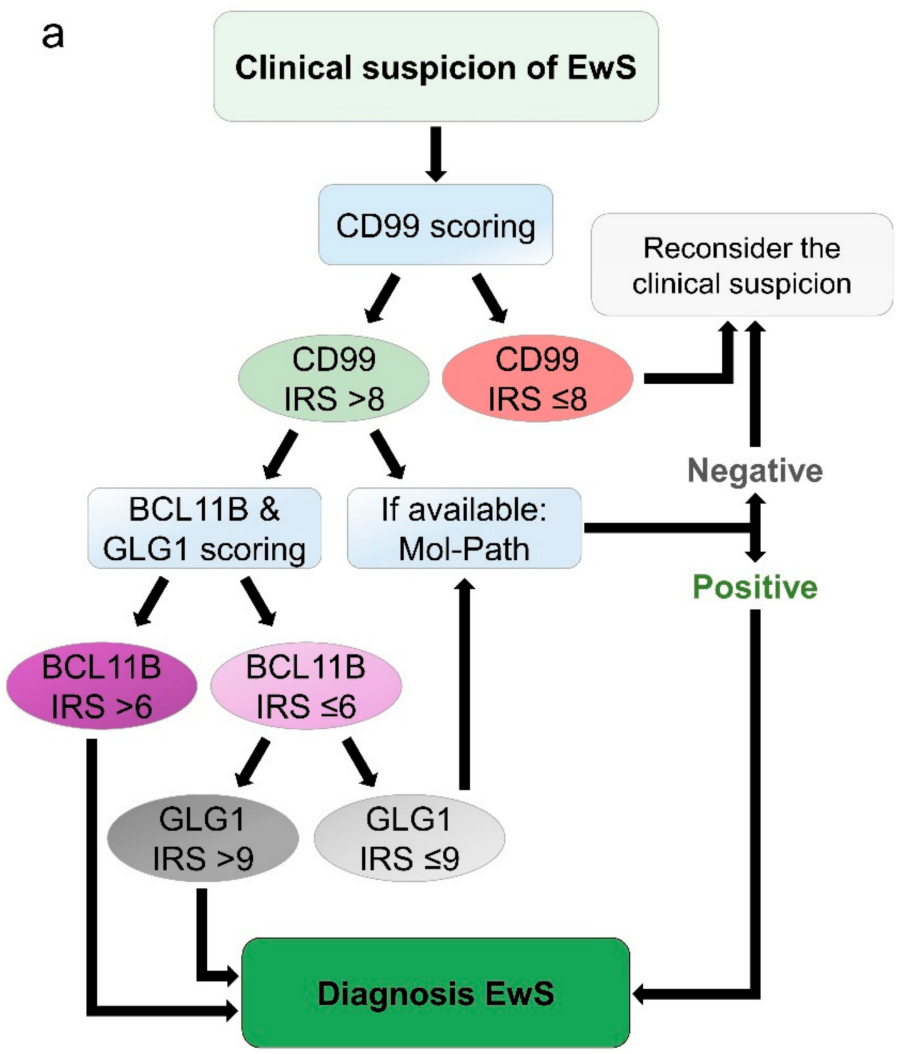

Figure 4. Cont. 


\section{b Performance of marker combination}

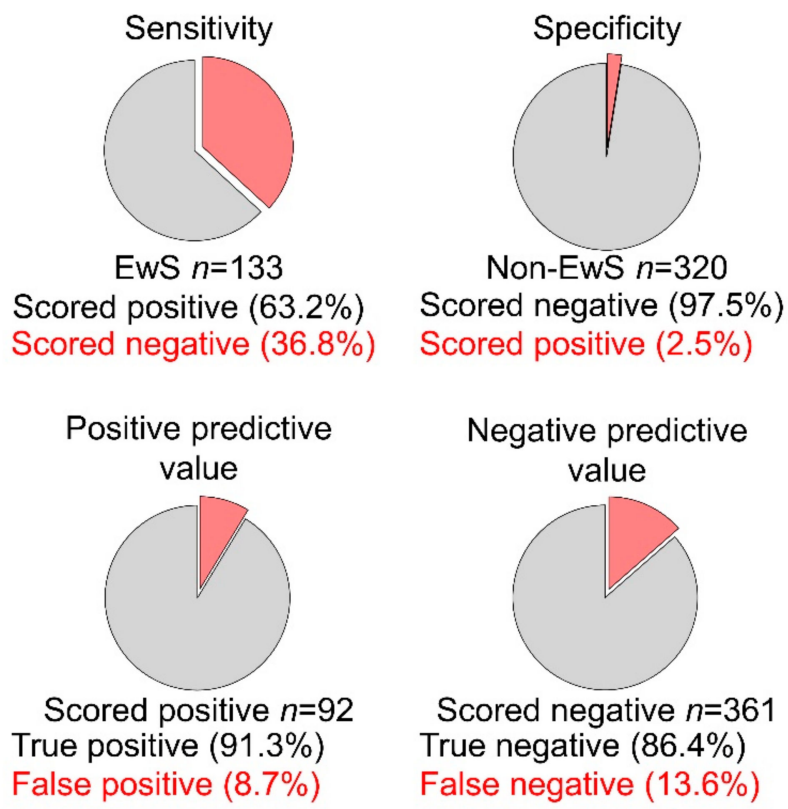

Figure 4. Proposed work-flow for immunohistochemical diagnosis of EwS. (a) Scheme of the proposed work-flow for immunohistochemical diagnosis of EwS; (b) pie charts indicating the performance of the proposed diagnostic procedure in the cohort of $133 \mathrm{EwS}$ and 320 samples of 11 differential diagnoses.

\section{Discussion}

Robust diagnostics are essential to quickly and correctly assign EwS patients to the appropriate therapy. After initial clinical presentation and imaging, the diagnostic workup of potential EwS patients is performed by surgical pathologists. As EwS belongs to the group of undifferentiated small-round-cell sarcomas [19], its histological phenotype is shared by several differential diagnoses [53].

In histopathological examination, evaluation of H\&E-stained slides is routinely followed by CD99 immunostaining [26], which is commonly positive in the vast majority of EwS cases [26,54]. In accordance, the CD99 IRS for 91\% (121/133) of EwS in our TMA cohort was $>8$.

However, even strong membranous CD99 immunoreactivity is not specific for EwS [28,55]. Indeed, $40 \%$ of non-EwS cases examined in the current study (128/320 samples, representing 11 distinct tumor entities) exhibited a strong CD99 immunostaining (IRS >8). Accordingly, in most institutions, the diagnosis of EwS is further validated by molecular pathology techniques, most commonly FISH to detect break-apart events in the EWSR1 gene [24]. Although a positive result is highly sensitive for EwS, some morphological mimics can exhibit break-apart events in the EWSR1 gene (e.g., DSRCT, AFH, and EWSR1-NFATc2-positive sarcomas) [39-41].

Another molecular technique is multiplex qRT-PCR to amplify pathognomonic FET-ETS fusion transcripts. However, due to the large variety of existing FET-ETS fusions in EwS [56], many of the currently used multiplex PCR sets likely do not cover all possible FET-ETS fusions. As a consequence, many institutions increasingly employ next-generation RNA-sequencing technologies to overcome these limitations. Yet, these techniques are not available or feasible in all cases, which is why a straight-forward immunohistochemical approach is still desirable.

Hence, many groups have evaluated several potential diagnostic markers such as FLI1, NKX2-2, and PAX7 that could be used instead of the highly unspecific marker CD99 [40,57,58]. However, to the best of our knowledge, none of these proposed IHC markers completely fulfills the requirements of providing very high sensitivity and specificity for EwS at the same time. While FLI1 is unable to confirm EwS cases with FET-non-FLI1 translocations [33,59], NKX2-2 and PAX7 lack specificity [60] and can be even strongly expressed in close morphological mimics such as EWSR1-NFATc2-positive 
sarcomas [40,57,58]. Besides, also Caveolin-1 [54,61], Cyclin-D1 [62], and NR0B1 [63] have been proposed as potential (auxiliary) IHC markers for EwS. While Cyclin-D1 and NR0B1 showed high sensitivity for EwS, they were reported as being not fully specific, which is why it was proposed to use them in an IHC marker panel [62,64]. Caveolin-1 is another highly sensitive IHC marker for EwS [54] but its specificity has- to the best of our knowledge - not been systematically assessed yet. The fact that Caveolin-1, Cyclin-D1, NKX2-2, NR0B1 and PAX7 are known FET-ETS target genes $[57,61,63,65,66]$ implies that not every FET-ETS target gene may serve as a highly specific auxiliary marker, since they may be also expressed at high levels in some morphological mimics.

To this end, we set out to identify highly specific auxiliary markers that can compensate the lack of specificity of CD99. By comparative transcriptome profiling of EwS cases and hundreds of samples from 20 morphological mimics, we previously identified three highly specific marker candidates, namely ATP1A1, BCL11B, and GLG1 [27]. Using IHC in a series of $47 \mathrm{EwS}$ and 127 non-EwS tumors from 11 distinct entities, we found that high BCL11B and/or high GLG1 expression in CD99-positive cases may be diagnostic for EwS, while ATP1A1 did neither raise the specificity nor sensitivity of this marker combination further [27]. However, even broader transcriptome analyses covering more than the investigated 19,702 genes and/or comparative proteomics analyses could yield additional auxiliary markers that are currently unknown.

In the current study, we confirmed the high specificity of BCL11B and GLG1 for EwS in a far larger and independent cohort of $133 \mathrm{EwS}$ and 320 non-EwS from 11 differential diagnoses, including 118 samples from close morphological mimics such as DSRCT, neuroblastoma, and rhabdomyosarcoma. This high number of samples enabled a refinement of the IRS cut-offs for both markers (BCL11B $>6$, GLG1 $>9$; compared to previously proposed cut-offs $>9$ for both markers). In conjunction with the highly sensitive marker CD99, our approach yielded a specificity of $97.5 \%$ and an accuracy of 87.4\% for diagnosing EwS solely by IHC. Also, EwS cases with EWSR1-ERG fusions exhibited high marker immunoreactivity.

However, it should be noted that in our cohort, 36.8\% of EwS cases could not be confirmed by this marker combination. If, in these cases, there is strong clinical suspicion of EwS, additional molecular approaches are mandatory for diagnosis. Additionally, in the current study, we used specific polyclonal antibodies against BCL11B and GLG1 (see methods). To further improve the accuracy of our diagnostic IHC approach and to reduce the risk of batch effects across different polyclonal antibodies, we recommend to systematically develop and improve monoclonal antibodies against both antigens that can be employed for IHC.

As tumor material is often limited, heterogeneously expressed markers can lead to misdiagnoses depending on the tumor fraction captured in a given sample. Hence, homogeneous expression of potential markers within tumors is desirable. For non-EwS cases, the proposed marker combination of CD99, BCL11B, and GLG1 yielded a consistent classification over all 3 cores taken from different areas of each tumor sample in $95.2 \%$. These findings suggest that the specificity of our approach is likely not compromised even when only little tumor material is available for diagnostics. Marker homogeneity in EwS was only moderate, possibly explaining the observed moderate sensitivity of our markers in our TMA cohort (representing each EwS sample with two $1 \mathrm{~mm}$ cores, in other words $1.6 \mathrm{~mm}^{2}$ tumor material). Potentially, the sensitivity might be even higher when more tumor material is available.

It should be noted that both auxiliary markers need to be carefully scored according to a modified Remmele and Stegner IRS. That is, both markers do not exhibit an 'all-or-nothing' expression pattern and rather display substantial expression variability in EwS and non-EwS cases. Thus, the actual immunoreactivity needs to be compared to visual analogous scales (see Baldauf et al. 2018 [27]), especially by pathologists with little experience with these markers. Yet, since most non-EwS cases do not exhibit any or only very weak positivity for both markers, and EwS exhibit very strong positivity, we believe that our auxiliary markers could easily be implemented on routine IHC workup of suspected EwS cases. 


\section{Materials and Methods}

\subsection{Human Samples and Ethics Approval}

The study was conducted in accordance with the Declaration of Helsinki. Formalin-fixed paraffin-embedded (FFPE) human tissue samples of EwS and differential diagnoses were retrieved from the archives of the Institute of Pathology of the LMU Munich (years 2009 to 2019) and collaborating institutions with approval of the ethics committee of the LMU Munich University Hospital (307-16 UE). Patient derived xenografts (PDX) were provided by the Childhood Solid Tumor Network [67], D. Surdez and O. Delattre (Paris, France), and A. Henssen (Berlin, Germany) with approval of the corresponding institutional review boards.

\subsection{Construction of Tissue Microarrays (TMA) and Immunohistochemistry (IHC)}

A total of 348 FFPE primary tissue samples and FFPE PDX samples from 64 pediatric sarcomas were collected. Only samples that could be diagnosed unambiguously using current state-of-the-art diagnostics for the respective tumor entity, were further processed. For each tumor, all FFPE blocks were examined in $\mathrm{H} \& \mathrm{E}$ stained slides and the tumor block containing the largest amount of vital tumor tissue was selected for TMA construction (three cores per tumor block, each with a diameter of $1 \mathrm{~mm}$, and internal controls). Additionally, TMAs with $144 \mathrm{EwS}$ samples and at least two cores per sample were obtained from W. Hartmann and U. Dirksen (Münster and Essen, Germany). The composition of the final cohort comprising $n=453$ samples is given in Table 1 .

For IHC, newly cut $4 \mu \mathrm{m}$ sections of TMAs or available open slides for $n=6$ EWSR1-ERG positive EwS samples, $n=1$ EWSR1-ATF1 positive angiomatoid fibrous histiocytoma (AFH), and $n=12$ PDX models were used. Antigen retrieval was performed with microwave treatment, $2 \times 15 \mathrm{~min}$ at $750 \mathrm{~W}$ using the antigen retrieval AR-10 solution (HK057-5K, DCS Innovative, Hamburg, Germany) for GLG1 and the Dako Target Retrieval Solution (S1699, Agilent, Santa Clara, CA, USA) for BCL11B. After rinsing the slides with pH 7.5 TRIS buffer (0.05 M; Sigma, Taufkirchen, Germany), endogenous peroxidase was blocked by $7.5 \%$ aqueous $\mathrm{H}_{2} \mathrm{O}_{2}$ solution at room temperature and blocking serum from the corresponding kits for $20 \mathrm{~min}$.

Slides were then incubated for $60 \mathrm{~min}$ with primary rabbit-anti-human antibodies anti-BCL11B (1:1000 dilution; ab70453, Abcam, Cambridge, UK), or anti-GLG1 (1:250 dilution; HPA010815, Atlas Antibodies, Bromma, Sweden). Then slides were incubated with a secondary anti-rabbit IgG antibody (ImmPress Reagent Kit, peroxidase-conjugated) followed by target detection using AEC plus chromogen for $10 \mathrm{~min}$ (K3461, Agilent).

For IHC staining of CD99, $4 \mu \mathrm{m}$ sections were incubated for $32 \mathrm{~min}$ with a monoclonal mouse-anti-human antibody (1:40 dilution; 12E7, Agilent) using the ultraView detection kit in a VENTANA BenchMark system (Roche, Basel, Switzerland).

\subsection{Evaluation of Immunoreactivity and Automated Cut-Off Finding}

Immunoreactivity of all TMAs and open slides for CD99, BCL11B, and GLG1 was semiquantitatively scored by three independent physician-scientists in analogy to scoring of hormone receptors with the immunoreactive score (IRS) established by Remmele and Stegner [47] with slight modifications of the grading of the percentage of positive tumor cells. First, the percentage of stained tumor cells was determined as the average of at least three high-power fields (40×) and rated on a scale of $0-4$ (grade $0=0 \%-19 \%$, grade $1=20 \%-39 \%$, grade $2=40 \%-59 \%$, grade $3=60 \%-79 \%$, and grade $4=80 \%-100 \%$ ). Second, for samples with marker immunoreactivity, the most representative intensity was determined (grade 1 = low, grade 2 = moderate, and grade $3=$ strong staining intensity) The product of these two grades defined the final IRS. After filtering out samples without representative tumor material on TMAs, the few samples with high inter-observer scoring deviation were revised and a consensus was built. High inter-observer scoring deviation was assumed if the sum of the absolute differences between the score of each observer and the mean IRS was at least as high as the mean 
IRS. Automated cut-off finding and combination testing were performed with an in-house VBA script implemented in Microsoft Excel (2016, 32-bit) as described in our discovery study [27].

\subsection{Evaluation of Heterogeneity of Intra-Tumoral Marker Expression}

To test whether the markers investigated in this study were heterogeneously expressed in a given differential diagnosis for EwS, we selected all tumor samples for which representative material was present in all three cores of the respective TMA for CD99, BCL11B, and GLG1 staining. In a next step, we evaluated for each core whether the IRS values for CD99, BCL11B, and GLG1 exceeded the predefined cut-offs ( $>8,>6,>9$, respectively, see Results section) to classify each core as either marker high/positive or low/negative. Then, we assessed whether the results were consistent across all three cores per tumor sample. As most EwS cases were represented by two cores per sample, the evaluation of marker expression heterogeneity for EwS was performed separately on samples with two cores present in each staining.

\subsection{RNA Extraction, Reverse Transcription, and Quantitative Real-Time PCR (qRT-PCR)}

To test for potential transcriptional regulation of BCL11B and GLG1 by EWSR1-ERG, we employed clones of three EWSR1-ERG positive EwS cell lines (CHLA25, EW3, and TC106) harboring a doxycycline inducible shRNA mediated EWSR1-ERG knockdown system. Wild-type CHLA25 and TC106 cells were obtained from the Children's Oncology Group (COG), and EW3 cells were kindly provided by O. Delattre. Cell line authenticity was confirmed by STR-profiling and mycoplasma contamination was ruled out by nested PCR. Total RNA was extracted from these EwS cell lines $96 \mathrm{~h}$ after induction of EWSR1-ERG knockdown using the NucleoSpin RNA kit (Macherey-Nagel, Düren, Germany). RNA was reversely transcribed using the High-Capacity cDNA Reverse Transcription Kit (Applied Biosystems, Foster City, CA, USA). qRT-PCRs were performed with 1:10 diluted cDNA and $0.5 \mu \mathrm{M}$ forward and reverse primers in SYBR Green PCR Master Mix (Applied Biosystems). Oligonucleotides were purchased from MWG Eurofins Genomics (Ebersberg, Germany). The following primer sequences were used:

BCL11B forward: 5'-ATGCCAGAATAGATGCCGG-3';

BCL11B reverse: $5^{\prime}$-CTCTATCTCCAGACCCTCGTC-3';

GLG1 forward: 5'-GTGGAGTGTAGAGATATAGTTGGC-3';

GLG1 reverse: 5'-ATCAGGTCCCCAGAGTCTATC-3';

RPLP0 forward: 5'-GAAACTCTGCATTCTCGCTTC-3';

$R P L P 0$ reverse: $5^{\prime}$-GGTGTAATCCGTCTCCACAG-3'.

Reactions were run on a BioRad CFX Connect instrument (Bio-Rad, Munich, Germany) with the following thermal conditions: heat activation $\left(95^{\circ} \mathrm{C}, 2 \mathrm{~min}\right)$, DNA denaturation $\left(95^{\circ} \mathrm{C}, 10 \mathrm{~s}\right)$, annealing and elongation $\left(60^{\circ} \mathrm{C}, 30 \mathrm{~s}\right), 49$ repeat cycles, final denaturation $\left(95^{\circ} \mathrm{C}, 30 \mathrm{~s}\right) . R P L P 0$ was used as housekeeping gene [68].

\section{Conclusions}

We anticipate that the here proposed diagnostic procedure (Figure 4a) will provide robust diagnosis in a large fraction of EwS cases even without any additional molecular diagnostic techniques, which may be of great benefit for patients, especially in settings in which molecular diagnostic approaches are not available or feasible.

Supplementary Materials: The following are available online at http://www.mdpi.com/2072-6694/12/3/644/s1, Figure S1: EWSR-ERG knockdown leads to decrease of BCL11B and GLG1 expression in EwS cell line models and PDX EwS models exhibit high immunoreactivity for BCL11B and GLG1; Figure S2: BCL11B and GLG1 show moderate intra-tumoral staining heterogeneity in EwS.

Author Contributions: M.F.O., M.D., M.C.B., and T.G.P.G. conceived the study; M.F.O. and T.G.P.G. wrote the paper and designed the figures and tables; M.F.O. performed statistical analyses; D.S., O.D., A.G.H., Ö.Ö., W.H., 
U.D., S.S., T.H., T.K. (Takayuki Kanaseki), S.B., and T.K. (Thomas Kirchner) provided FFPE samples; F.S.W., T.P., M.C.B., M.M.L.K., L.R.-P., M.K., F.C.-A., J.S.G., S.O., J.L., A.M. helped in sample acquisition, sample preparation, and/or experimental procedures; M.F.O., M.D., and T.L.B.H. scored the TMAs, supported by J.M.; T.K. (Thomas Kirchner) provided laboratory infrastructure and histological guidance; T.G.P.G. initiated and supervised the study. All authors have read and agreed to the published version of the manuscript.

Funding: The laboratory of TGPG is supported by grants from the 'Verein zur Förderung von Wissenschaft und Forschung an der Medizinischen Fakultät der LMU München (WiFoMed)', by LMU Munich's Institutional Strategy LMUexcellent within the framework of the German Excellence Initiative, the 'Mehr LEBEN für krebskranke Kinder-Bettina-Bräu-Stiftung', the Friedrich-Baur foundation, the Matthias-Lackas foundation, the Barbara und Hubertus Trettner foundation, the Dr. Leopold und Carmen Ellinger foundation, the Dr. Rolf M. Schwiete foundation, the Gert \& Susanna Mayer foundation, the Deutsche Forschungsgemeinschaft (DFG 391665916), and by the German Cancer Aid (DKH-70112257). TLBH and MK were supported by scholarships of the German Cancer Aid. MCB was supported by a scholarship of the German National Academic Foundation. MD was supported by a scholarship of the Deutsche Stiftung für junge Erwachsene mit Krebs. JL, JM and MK were supported by a scholarships of the Dr. Rudolf und Brigitte Zenner Stiftung. UD is supported by the German Cancer Aid (DKH-108128, DKH-70112018, DKH-701134219), the Barbara und Hubertus Trettner foundation, and the Gert \& Susanna Mayer foundation.

Acknowledgments: We thank Andrea Sendelhofert, Anja Heier, Stefanie Stein, Mario Gipp, and Heike Prelle for excellent technical assistance.

Conflicts of Interest: The authors declare no conflict of interest.

\section{References}

1. Grünewald, T.G.P.; Cidre-Aranaz, F.; Surdez, D.; Tomazou, E.M.; de Álava, E.; Kovar, H.; Sorensen, P.H.; Delattre, O.; Dirksen, U. Ewing sarcoma. Nat. Rev. Dis. Primers 2018, 4, 5. [CrossRef] [PubMed]

2. Kaatsch, P.; Strothotte, J.; Becker, C.; Bielack, S.; Dirksen, U.; Blettner, M. Pediatric bone tumors in Germany from 1987 to 2011: Incidence rates, time trends and survival. Acta Oncol. 2016, 55, 1145-1151. [CrossRef] [PubMed]

3. Nakata, K.; Ito, Y.; Magadi, W.; Bonaventure, A.; Stiller, C.A.; Katanoda, K.; Matsuda, T.; Miyashiro, I.; Pritchard-Jones, K.; Rachet, B. Childhood cancer incidence and survival in Japan and England: A populationbased study (1993-2010). Cancer Sci. 2018, 109, 422-434. [CrossRef] [PubMed]

4. Rochefort, P.; Italiano, A.; Laurence, V.; Penel, N.; Lardy-Cleaud, A.; Mir, O.; Chevreau, C.; Bertucci, F.; Bompas, E.; Chaigneau, L.; et al. A Retrospective Multicentric Study of Ewing Sarcoma Family of Tumors in Patients Older Than 50: Management and Outcome. Sci. Rep. 2017, 7, 17917. [CrossRef] [PubMed]

5. Ahmad, R.; Mayol, B.R.; Davis, M.; Rougraff, B.T. Extraskeletal Ewing's sarcoma. Cancer 1999, 85, 725-731. [CrossRef]

6. Duchman, K.R.; Gao, Y.; Miller, B.J. Prognostic factors for survival in patients with Ewing's sarcoma using the surveillance, epidemiology, and end results (SEER) program database. Cancer Epidemiol. 2015, 39, 189-195. [CrossRef]

7. Zhang, J.; Pan, Z.; Yang, J.; Yan, X.; Li, Y.; Lyu, J. A nomogram for determining the disease-specific survival in Ewing sarcoma: A population study. BMC Cancer 2019, 19. [CrossRef]

8. Bosma, S.E.; Ayu, O.; Fiocco, M.; Gelderblom, H.; Dijkstra, P.D.S. Prognostic factors for survival in Ewing sarcoma: A systematic review. Surg. Oncol. 2018, 27, 603-610. [CrossRef]

9. Gaspar, N.; Hawkins, D.S.; Dirksen, U.; Lewis, I.J.; Ferrari, S.; Le Deley, M.-C.; Kovar, H.; Grimer, R.; Whelan, J.; Claude, L.; et al. Ewing Sarcoma: Current Management and Future Approaches Through Collaboration. J. Clin. Oncol. 2015, 33, 3036-3046. [CrossRef]

10. Dirksen, U.; Brennan, B.; Le Deley, M.-C.; Cozic, N.; van den Berg, H.; Bhadri, V.; Brichard, B.; Claude, L.; Craft, A.; Amler, S.; et al. High-Dose Chemotherapy Compared With Standard Chemotherapy and Lung Radiation in Ewing Sarcoma With Pulmonary Metastases: Results of the European Ewing Tumour Working Initiative of National Groups, 99 Trial and EWING 2008. J. Clin. Oncol. 2019, 37, 3192-3202. [CrossRef]

11. PDQ Pediatric Treatment Editorial Board. Ewing Sarcoma Treatment (PDQß): Health Professional Version. In PDQ Cancer Information Summaries; National Cancer Institute (US): Bethesda, MD, USA, 2002.

12. Kridis, W.B.; Toumi, N.; Chaari, H.; Khanfir, A.; Ayadi, K.; Keskes, H.; Boudawara, T.; Daoud, J.; Frikha, M. A Review of Ewing Sarcoma Treatment: Is it Still a Subject of Debate? Rev. Recent Clin. Trials 2017, 12, 19-23. [CrossRef] [PubMed] 
13. Andreou, D.; Ranft, A.; Gosheger, G.; Timmermann, B.; Ladenstein, R.; Hartmann, W.; Bauer, S.; Baumhoer, D.; van den Berg, H.; Dijkstra, P.D.S.; et al. GPOH-Euro-EWING99 consortium Which Factors Are Associated with Local Control and Survival of Patients with Localized Pelvic Ewing's Sarcoma? A Retrospective Analysis of Data from the Euro-EWING99 Trial. Clin. Orthop. 2020, 478, 290-302. [CrossRef] [PubMed]

14. Whelan, J.; Le Deley, M.-C.; Dirksen, U.; Le Teuff, G.; Brennan, B.; Gaspar, N.; Hawkins, D.S.; Amler, S.; Bauer, S.; Bielack, S.; et al. High-Dose Chemotherapy and Blood Autologous Stem-Cell Rescue Compared With Standard Chemotherapy in Localized High-Risk Ewing Sarcoma: Results of Euro-E.W.I.N.G.99 and Ewing-2008. J. Clin. Oncol. 2018, JCO2018782516. [CrossRef] [PubMed]

15. Womer, R.B.; West, D.C.; Krailo, M.D.; Dickman, P.S.; Pawel, B.R.; Grier, H.E.; Marcus, K.; Sailer, S.; Healey, J.H.; Dormans, J.P.; et al. Randomized controlled trial of interval-compressed chemotherapy for the treatment of localized Ewing sarcoma: A report from the Children's Oncology Group. J. Clin. Oncol. 2012, 30, 4148-4154. [CrossRef]

16. Mascarenhas, L.; Felgenhauer, J.L.; Bond, M.C.; Villaluna, D.; Femino, J.D.; Laack, N.N.; Ranganathan, S.; Meyer, J.; Womer, R.B.; Gorlick, R.; et al. Pilot Study of Adding Vincristine, Topotecan, and Cyclophosphamide to Interval-Compressed Chemotherapy in Newly Diagnosed Patients With Localized Ewing Sarcoma: A Report From the Children's Oncology Group. Pediatr. Blood Cancer 2016, 63, 493-498. [CrossRef]

17. Alonso, L.; Navarro-Perez, V.; Sanchez-Muñoz, A.; Alba, E. Time to diagnosis of ewing tumors in children and adolescents is not associated with metastasis or survival. J. Clin. Oncol. 2014, 4020, 32. [CrossRef]

18. Brasme, J.-F.; Chalumeau, M.; Oberlin, O.; Valteau-Couanet, D.; Gaspar, N. Time to diagnosis of Ewing tumors in children and adolescents is not associated with metastasis or survival: A prospective multicenter study of 436 patients. J. Clin. Oncol. 2014, 32, 1935-1940. [CrossRef]

19. Ewing, J. The Classic: Diffuse Endothelioma of Bone. Clin. Orthop. 2006, 450, 25-27. [CrossRef]

20. Hung, Y.P.; Lee, J.P.; Bellizzi, A.M.; Hornick, J.L. PHOX2B reliably distinguishes neuroblastoma among small round blue cell tumours. Histopathology 2017, 71, 786-794. [CrossRef]

21. Parham, D.M. Modern Diagnosis of Small Cell Malignancies of Children. Surg. Pathol. Clin. 2010, 3, 515-551. [CrossRef]

22. Sbaraglia, M.; Righi, A.; Gambarotti, M.; Dei Tos, A.P. Ewing sarcoma and Ewing-like tumors. Virchows Arch. 2020, 476, 109-119. [CrossRef] [PubMed]

23. Li, X.; Li, W.; Mo, W.; Yang, Z. Acute lymphoblastic leukemia arising after treatment of Ewing sarcoma was misdiagnosed as bone marrow metastasis of Ewing sarcoma: A case report. Medicine (Baltimore) 2018, 97, e9644. [CrossRef] [PubMed]

24. Machado, I.; Noguera, R.; Pellin, A.; Lopez-Guerrero, J.A.; Piqueras, M.; Navarro, S.; Llombart-Bosch, A. Molecular diagnosis of Ewing sarcoma family of tumors: A comparative analysis of 560 cases with FISH and RT-PCR. Diagn. Mol. Pathol. Am. J. Surg. Pathol. Part B 2009, 18, 189-199. [CrossRef]

25. Fisher, C. The diversity of soft tissue tumours with EWSR1 gene rearrangements: A review. Histopathology 2014, 64, 134-150. [CrossRef] [PubMed]

26. Ambros, I.M.; Ambros, P.F.; Strehl, S.; Kovar, H.; Gadner, H.; Salzer-Kuntschik, M. MIC2 is a specific marker for Ewing's sarcoma and peripheral primitive neuroectodermal tumors. Evidence for a common histogenesis of Ewing's sarcoma and peripheral primitive neuroectodermal tumors from MIC2 expression and specific chromosome aberration. Cancer 1991, 67, 1886-1893. [CrossRef]

27. Baldauf, M.C.; Orth, M.F.; Dallmayer, M.; Marchetto, A.; Gerke, J.S.; Rubio, R.A.; Kiran, M.M.; Musa, J.; Knott, M.M.L.; Ohmura, S.; et al. Robust diagnosis of Ewing sarcoma by immunohistochemical detection of super-enhancer-driven EWSR1-ETS targets. Oncotarget 2018, 9, 1587-1601. [CrossRef]

28. Zaccarini, D.J.; Deng, X.; Tull, J.; Maciak, C.; Valente, A.L.; Zhang, S. Expression of TLE-1 and CD99 in Carcinoma: Pitfalls in Diagnosis of Synovial Sarcoma. Appl. Immunohistochem. Mol. Morphol. AIMM 2018, 26, 368-373. [CrossRef]

29. Chen, D.; Camponeschi, A.; Wu, Q.; Gerasimcik, N.; Li, H.; Shen, X.; Tan, Y.; Sjögren, H.; Nordlund, J.; Lönnerholm, G.; et al. CD99 expression is strongly associated with clinical outcome in children with B-cell precursor acute lymphoblastic leukaemia. Br. J. Haematol. 2019, 184, 418-423. [CrossRef]

30. Kazlouskaya, V.; Malhotra, S.; Kabigting, F.D.; Lal, K.; Elston, D.M. CD99 expression in dermatofibrosarcoma protuberans and dermatofibroma. Am. J. Dermatopathol. 2014, 36, 392-396. [CrossRef] 
31. Richardson, A.I.; Zhang, D.; Woodroof, J.; Cui, W. p53 expression in large B-cell lymphomas with MYC extra copies and CD99 expression in large B-cell lymphomas in relation to MYC status. Hum. Pathol. 2019, 86, 21-31. [CrossRef]

32. Delattre, O.; Zucman, J.; Plougastel, B.; Desmaze, C.; Melot, T.; Peter, M.; Kovar, H.; Joubert, I.; de Jong, P.; Rouleau, G. Gene fusion with an ETS DNA-binding domain caused by chromosome translocation in human tumours. Nature 1992, 359, 162-165. [CrossRef] [PubMed]

33. Zucman, J.; Melot, T.; Desmaze, C.; Ghysdael, J.; Plougastel, B.; Peter, M.; Zucker, J.M.; Triche, T.J.; Sheer, D.; Turc-Carel, C. Combinatorial generation of variable fusion proteins in the Ewing family of tumours. EMBO J. 1993, 12, 4481-4487. [CrossRef] [PubMed]

34. Tirode, F.; Surdez, D.; Ma, X.; Parker, M.; Le Deley, M.C.; Bahrami, A.; Zhang, Z.; Lapouble, E.; Grossetête-Lalami, S.; Rusch, M.; et al. Genomic landscape of Ewing sarcoma defines an aggressive subtype with co-association of STAG2 and TP53 mutations. Cancer Discov. 2014, 4, 1342-1353. [CrossRef] [PubMed]

35. Bridge, R.S.; Rajaram, V.; Dehner, L.P.; Pfeifer, J.D.; Perry, A. Molecular diagnosis of Ewing sarcoma/primitive neuroectodermal tumor in routinely processed tissue: A comparison of two FISH strategies and RT-PCR in malignant round cell tumors. Mod. Pathol. 2006, 19, 1-8. [CrossRef] [PubMed]

36. Gautam, U.; Srinivasan, R.; Rajwanshi, A.; Bansal, D.; Marwaha, R.K.; Vasishtha, R.K. Reverse Transcriptase-Polymerase Chain Reaction as an Ancillary Molecular Technique in the Diagnosis of Small Blue Round Cell Tumors by Fine-Needle Aspiration Cytology. Am. J. Clin. Pathol. 2010, 133, 633-645. [CrossRef] [PubMed]

37. Ng, T.L.; O'Sullivan, M.J.; Pallen, C.J.; Hayes, M.; Clarkson, P.W.; Winstanley, M.; Sorensen, P.H.B.; Nielsen, T.O.; Horsman, D.E. Ewing sarcoma with novel translocation $\mathrm{t}(2 ; 16)$ producing an in-frame fusion of FUS and FEV. J. Mol. Diagn. JMD 2007, 9, 459-463. [CrossRef]

38. Chen, S.; Deniz, K.; Sung, Y.-S.; Zhang, L.; Dry, S.; Antonescu, C.R. Ewing sarcoma with ERG gene rearrangements: A molecular study focusing on the prevalence of FUS-ERG and common pitfalls in detecting EWSR1-ERG fusions by FISH. Genes Chromosomes Cancer 2016, 55, 340-349. [CrossRef]

39. Papp, G.; Mihály, D.; Sápi, Z. Unusual Signal Patterns of Break-apart FISH Probes Used in the Diagnosis of Soft Tissue Sarcomas. Pathol. Oncol. Res. 2017, 23, 863-871. [CrossRef]

40. Baldauf, M.C.; Gerke, J.S.; Orth, M.F.; Dallmayer, M.; Baumhoer, D.; de Alava, E.; Hartmann, W.; Kirchner, T.; Grünewald, T.G.P. Are EWSR1-NFATc2-positive sarcomas really Ewing sarcomas? Mod. Pathol. 2018, 31, 997-999. [CrossRef]

41. Koelsche, C.; Kriegsmann, M.; Kommoss, F.K.F.; Stichel, D.; Kriegsmann, K.; Vokuhl, C.; Grünewald, T.G.P.; Romero-Pérez, L.; Kirchner, T.; de Alava, E.; et al. DNA methylation profiling distinguishes Ewing-like sarcoma with EWSR1-NFATc2 fusion from Ewing sarcoma. J. Cancer Res. Clin. Oncol. 2019, 145, 1273-1281. [CrossRef]

42. Yau, D.T.W.; Chan, J.K.C.; Bao, S.; Zheng, Z.; Lau, G.T.C.; Chan, A.C.L. Bone Sarcoma With EWSR1-NFATC2 Fusion: Sarcoma With Varied Morphology and Amplification of Fusion Gene Distinct From Ewing Sarcoma. Int. J. Surg. Pathol. 2019, 27, 561-567. [CrossRef] [PubMed]

43. Lam, S.W.; Cleton-Jansen, A.-M.; Cleven, A.H.G.; Ruano, D.; van Wezel, T.; Szuhai, K.; Bovée, J.V.M.G. Molecular Analysis of Gene Fusions in Bone and Soft Tissue Tumors by Anchored Multiplex PCR-Based Targeted Next-Generation Sequencing. J. Mol. Diagn. JMD 2018, 20, 653-663. [CrossRef] [PubMed]

44. Koelsche, C.; Hartmann, W.; Schrimpf, D.; Stichel, D.; Jabar, S.; Ranft, A.; Reuss, D.E.; Sahm, F.; Jones, D.T.W.; Bewerunge-Hudler, M.; et al. Array-based DNA-methylation profiling in sarcomas with small blue round cell histology provides valuable diagnostic information. Mod. Pathol. 2018, 31, 1246-1256. [CrossRef] [PubMed]

45. Wiles, E.T.; Lui-Sargent, B.; Bell, R.; Lessnick, S.L. BCL11B is up-regulated by EWS/FLI and contributes to the transformed phenotype in Ewing sarcoma. PLoS ONE 2013, 8, e59369. [CrossRef] [PubMed]

46. Mourelatos, Z.; Gonatas, J.O.; Nycum, L.M.; Gonatas, N.K.; Biegel, J.A. Assignment of the GLG1 gene for MGF-160, a fibroblast growth factor and E-selectin binding membrane sialoglycoprotein of the Golgi apparatus, to chromosome 16q22-q23 by fluorescence in situ hybridization. Genomics 1995, 28, 354-355. [CrossRef]

47. Remmele, W.; Stegner, H.E. Recommendation for uniform definition of an immunoreactive score (IRS) for immunohistochemical estrogen receptor detection (ER-ICA) in breast cancer tissue. Pathologe 1987, 8, 138-140. 
48. Kervarrec, T.; Tallet, A.; Miquelestorena-Standley, E.; Houben, R.; Schrama, D.; Gambichler, T.; Berthon, P.; Le Corre, Y.; Hainaut-Wierzbicka, E.; Aubin, F.; et al. Morphologic and immunophenotypical features distinguishing Merkel cell polyomavirus-positive and negative Merkel cell carcinoma. Mod. Pathol. 2019. [CrossRef]

49. Vaikari, V.P.; Du, Y.; Wu, S.; Zhang, T.; Metzeler, K.; Batcha, A.M.N.; Herold, T.; Hiddemann, W.; Akhtari, M.; Alachkar, H. Clinical and preclinical characterization of CD99 isoforms in acute myeloid leukemia. Haematologica 2019. [CrossRef]

50. Cardoso, L.C.; Soares, R.d.S.; Laurentino, T.d.S.; Lerario, A.M.; Marie, S.K.N.; Oba-Shinjo, S.M. CD99 Expression in Glioblastoma Molecular Subtypes and Role in Migration and Invasion. Int. J. Mol. Sci. 2019, 20. [CrossRef]

51. Sorensen, P.H.; Liu, X.F.; Delattre, O.; Rowland, J.M.; Biggs, C.A.; Thomas, G.; Triche, T.J. Reverse transcriptase PCR amplification of EWS/FLI-1 fusion transcripts as a diagnostic test for peripheral primitive neuroectodermal tumors of childhood. Diagn. Mol. Pathol. Am. J. Surg. Pathol. Part B 1993, 2, 147-157. [CrossRef]

52. Paulussen, M.; Bielack, S.; Jürgens, H.; Jost, L. ESMO Guidelines Working Group Ewing's sarcoma of the bone: ESMO clinical recommendations for diagnosis, treatment and follow-up. Ann. Oncol. 2008, 19, ii97-ii98. [CrossRef] [PubMed]

53. Carter, C.S.; Patel, R.M. Important Recently Characterized Non-Ewing Small Round Cell Tumors. Surg. Pathol. Clin. 2019, 12, 191-215. [CrossRef] [PubMed]

54. Llombart-Bosch, A.; Machado, I.; Navarro, S.; Bertoni, F.; Bacchini, P.; Alberghini, M.; Karzeladze, A.; Savelov, N.; Petrov, S.; Alvarado-Cabrero, I.; et al. Histological heterogeneity of Ewing's sarcoma/PNET: An immunohistochemical analysis of 415 genetically confirmed cases with clinical support. Virchows Arch. 2009, 455, 397-411. [CrossRef] [PubMed]

55. Sadeghipour, A.; Abdi, N.; Babaheidarian, P. CD99: A potential Diagnostic Marker for Differentiating Sub-ependymal Giant Cell Astrocytoma from Other Mimickers: A Report of Five Cases. Iran. J. Pathol. 2017, 12, 286-290.

56. Antonescu, C. Round cell sarcomas beyond Ewing: Emerging entities. Histopathology 2014, 64, $26-37$. [CrossRef] [PubMed]

57. Charville, G.W.; Wang, W.-L.; Ingram, D.R.; Roy, A.; Thomas, D.; Patel, R.M.; Hornick, J.L.; van de Rijn, M.; Lazar, A.J. EWSR1 fusion proteins mediate PAX7 expression in Ewing sarcoma. Mod. Pathol. 2017, 30, 1312-1320. [CrossRef]

58. Toki, S.; Wakai, S.; Sekimizu, M.; Mori, T.; Ichikawa, H.; Kawai, A.; Yoshida, A. PAX7 immunohistochemical evaluation of Ewing sarcoma and other small round cell tumours. Histopathology 2018, 73, 645-652. [CrossRef]

59. Crompton, B.D.; Stewart, C.; Taylor-Weiner, A.; Alexe, G.; Kurek, K.C.; Calicchio, M.L.; Kiezun, A.; Carter, S.L.; Shukla, S.A.; Mehta, S.S.; et al. The genomic landscape of pediatric Ewing sarcoma. Cancer Discov. 2014, 4, 1326-1341. [CrossRef]

60. Hung, Y.P.; Fletcher, C.D.; Hornick, J.L. Evaluation of NKX2-2 Expression in Round Cell Sarcomas and Other Tumors with EWSR1 Rearrangement: Imperfect Specificity for Ewing Sarcoma. Mod. Pathol. 2016, 29, 370-380. Available online: https:/www-nature-com.emedien.ub.uni-muenchen.de/articles/ modpathol201631 (accessed on 21 August 2019). [CrossRef]

61. Tirado, O.M.; Mateo-Lozano, S.; Villar, J.; Dettin, L.E.; Llort, A.; Gallego, S.; Ban, J.; Kovar, H.; Notario, V. Caveolin-1 (CAV1) is a target of EWS/FLI-1 and a key determinant of the oncogenic phenotype and tumorigenicity of Ewing's sarcoma cells. Cancer Res. 2006, 66, 9937-9947. [CrossRef]

62. Magro, G.; Brancato, F.; Musumeci, G.; Alaggio, R.; Parenti, R.; Salvatorelli, L. Cyclin D1 is a useful marker for soft tissue Ewing's sarcoma/peripheral Primitive Neuroectodermal Tumor in children and adolescents: A comparative immunohistochemical study with rhabdomyosarcoma. Acta Histochem. 2015, 117, 460-467. [CrossRef] [PubMed]

63. Shibuya, R.; Matsuyama, A.; Nakamoto, M.; Shiba, E.; Kasai, T.; Hisaoka, M. The combination of CD99 and NKX2.2, a transcriptional target of EWSR1-FLI1, is highly specific for the diagnosis of Ewing sarcoma. Virchows Arch. 2014, 465, 599-605. [CrossRef] [PubMed]

64. Magro, G.; Longo, F.R.; Angelico, G.; Spadola, S.; Amore, F.F.; Salvatorelli, L. Immunohistochemistry as potential diagnostic pitfall in the most common solid tumors of children and adolescents. Acta Histochem. 2015, 117, 397-414. [CrossRef] [PubMed] 
65. Gangwal, K.; Sankar, S.; Hollenhorst, P.C.; Kinsey, M.; Haroldsen, S.C.; Shah, A.A.; Boucher, K.M.; Watkins, W.S.; Jorde, L.B.; Graves, B.J.; et al. Microsatellites as EWS/FLI response elements in Ewing's sarcoma. Proc. Natl. Acad. Sci. USA 2008, 105, 10149-10154. [CrossRef] [PubMed]

66. Sanchez, G.; Bittencourt, D.; Laud, K.; Barbier, J.; Delattre, O.; Auboeuf, D.; Dutertre, M. Alteration of cyclin D1 transcript elongation by a mutated transcription factor up-regulates the oncogenic D1b splice isoform in cancer. Proc. Natl. Acad. Sci. USA 2008, 105, 6004-6009. [CrossRef] [PubMed]

67. Stewart, E.; Federico, S.M.; Chen, X.; Shelat, A.A.; Bradley, C.; Gordon, B.; Karlstrom, A.; Twarog, N.R.; Clay, M.R.; Bahrami, A.; et al. Orthotopic patient-derived xenografts of paediatric solid tumours. Nature 2017, 549, 96-100. [CrossRef] [PubMed]

68. Musa, J.; Cidre-Aranaz, F.; Aynaud, M.-M.; Orth, M.F.; Knott, M.M.L.; Mirabeau, O.; Mazor, G.; Varon, M.; Hölting, T.L.B.; Grossetête, S.; et al. Cooperation of cancer drivers with regulatory germline variants shapes clinical outcomes. Nat. Commun. 2019, 10, 4128. [CrossRef]

(C) 2020 by the authors. Licensee MDPI, Basel, Switzerland. This article is an open access article distributed under the terms and conditions of the Creative Commons Attribution (CC BY) license (http://creativecommons.org/licenses/by/4.0/). 